VESTIBOLOGY

\title{
Utricular hypofunction in patients with type 2 diabetes mellitus
}

\author{
Ipofunzione utricolare in pazienti con diabete mellito di tipo 2 \\ K. JÁUREGUI-RENAUD' ${ }^{1}$, C. ARANDA-MORENO', ${ }^{1,}$, A. HERRERA-RANGEL ${ }^{1}$ \\ ${ }^{1}$ Unidad de Investigación Médica en Otoneurología; ${ }^{2}$ Hospital General Regional no.72, Instituto Mexicano del \\ Seguro Social, México
}

\begin{abstract}
SUMMARY
The aim of this study was to assess the function of the utricle and horizontal semicircular canals in patients with type 2 diabetes mellitus receiving primary health care, with/without a history of falls. 101 patients with type 2 diabetes mellitus, 34 to 84 years old (26 with and 75 without a history of falls) and 51 healthy volunteers (40-83 years old) accepted to participate. They denied having a history of dizziness, vertigo, unsteadiness, hearing loss, or neurological disorders. None of them were seeking care due to sensory or balance decline. After a clinical evaluation and report of symptoms related to balance using a standardised questionnaire, lateral canal function was assessed by sinusoidal rotation at $0.16 \mathrm{~Hz}$ and $1.28 \mathrm{~Hz}\left(60^{\circ} / \mathrm{sec}\right.$ peak velocity), otolith function was assessed by static visual vertical (average of 10 trials) and dynamic visual vertical during unilateral centrifugation $(300 \% \mathrm{sec}$ at $3.5 \mathrm{~cm})$ and static posturography was performed on hard/ soft surface with eyes open/closed. Compared to healthy volunteers, patients showed decreased responses to unilateral centrifugation, but similar responses to horizontal canal stimuli (independently of age, peripheral neuropathy or a history of falls) (ANCoVA p < 0.05) and a larger sway area with a lengthier sway path. Compared to patients with no falls, patients with falls had a higher female/male ratio and a higher frequency of score $\geq 4$ on the questionnaire of symptoms related to balance, but similar age, body mass index and frequency of peripheral neuropathy. In patients with type 2 diabetes mellitus, receiving primary healthcare who are not seeking care due to sensory or balance decline, utricular function may be impaired even in the absence of horizontal canal dysfunction or a history of falls.
\end{abstract}

KEY WORDS: Diabetes mellitus • Vestibular function • Falls

\section{RIASSUNTO}

L'obiettivo di questo studio è stato quello di valutare la funzione utricolare e la funzione dei canali semicircolari laterali in pazienti con diabete mellito di tipo 2, con o senza cadute, afferenti all'assistenza sanitaria di base. Sono stati arruolati 101 pazienti con diabete mellito di tipo 2 (26 con storia di cadute, 75 senza), di età compresa tra 34 e 84 anni, e 51 volontari sani di età compresa tra 40 e 83 anni, i quali hanno negato vertigini, capogiri, instabilità, ipoacusia o disordini neurologici. Nessuno di loro era in cerca di cure per deficit sensoriali o dell'equilibrio. Dopo aver effettuato una valutazione clinica e dopo aver indagato i sintomi relativi alla sfera dell'equilibrio con l'ausilio di un questionario standardizzato, la funzione dei canali semicircolari laterali è stata studiata con il test sinusoidale alle velocità di 0,16 $\mathrm{Hz}$ e $1,28 \mathrm{~Hz}$ (il picco della velocità è stato fissato a $60 \%$ ); la funzione otolitica, invece, è stata studiata con la verticale visiva soggettiva, determinata sia tramite test statico sia tramite test dinamico, durante centrifugazione unilaterale $(300 \% \mathrm{~s} \mathrm{a} 3.5 \mathrm{~cm})$; è stata eseguita inoltre la posturografia statica, su pedana soffice e dura, ad occhi aperti e chiusi. Confrontando i risultati ottenuti nei pazienti diabetici e in quelli sani, i pazienti diabetici hanno mostrato risposte inferiori alla centrifugazione unilaterale, ma risposte simili alla stimolazione dei canali semicircolari laterali, indipendentemente da età, neuropatie periferiche o storia di cadute (ANCoVA $p<0.05)$. I pazienti con storia di cadute, rispetto a quelli senza storia di cadute, erano per lo più donne e hanno raggiunto più facilmente un punteggio maggiore o pari a 4 al questionario sui sintomi relativi al senso dell'equilibrio; tuttavia i due gruppi hanno mostrato simili età, indice di massa corporea e neuropatia periferica. Nei pazienti con diabete di tipo 2, afferenti all'assistenza sanitaria di base e non in cerca di cure per deficit sensoriali o dell'equilibrio, la funzione utricolare potrebbe essere alterata, anche in assenza di disfunzione dei canali semicircolari laterali o di storia di cadute.

PAROLE CHIAVE: Diabete mellito $\bullet$ Funzione vestibolare $\bullet$ Cadute

Acta Otorhinolaryngol Ital 2017;37:430-435

\section{Introduction}

To maintain balance, any perturbation of stance must be opposed by coordinated motor responses, requiring sensory information from multiple sources, including somatosensory, vestibular and visual inputs. Evidence has shown that individuals with somatosensory or vestibular deficit are limited in their ability to re-weight postural sensory inputs ${ }^{12}$, with the risk of falling.

Falls occur as a result of complex interactions between intrinsic (demographic and biological factors) and extrinsic 
factors (environmental and behavioural factors) ${ }^{3}$. Diabetes mellitus is an independent risk factor for falling, particularly in the elderly ${ }^{45}$. Patients with diabetes mellitus may have sensory deficits as well as unrecognised postural instability ${ }^{6-9}$. In this group of patients, the frequency of symptoms related to balance has been associated with both the time elapsed since the diabetes was diagnosed and the history of peripheral neuropathy and retinopathy ${ }^{9}$. Studies in murine models of acquired diabetes have shown deterioration of utricular function, with increased latency and decreased amplitude of the short latency vestibular evoked potentials in response to linear acceleration ${ }^{10}$, as well as a high incidence of osmophilic inclusion bodies in the saccular and utricular nerves, with disrupted myelinsheath lamellae ${ }^{11}$. Accordingly, in patients with type 2 diabetes mellitus vestibular dysfunction on clinical tests has been observed ${ }^{12-14}$. However, studies evaluating the otolith function of patients with type 2 diabetes mellitus are scarce, even more so in patients receiving primary health care. In a recent study, otoconial organ impairment by cervical and ocular vestibular-evoked myogenic potentials was recognised in $50 \%$ of adult patients with type 2 diabetes mellitus (saccular, utricular or both organs) ${ }^{14}$.

The aim of this study was to assess the function of the urticular macula and the horizontal semicircular canals, as well as postural stability of patients with type 2 diabetes mellitus receiving primary health care, who were not seeking medical care due to sensory or balance decline, with/without a history of falls, compared to age-matched controls.

\section{Materials and methods}

After approval of the research protocol by the Research and Ethics Committees of the Institution, informed consent was obtained from all participants and the study was performed according to the Declaration of Helsinki and amendments. A total of 101 consecutive patients with type 2 diabetes mellitus, who met selection criteria (age range 34 to 84 years, mean $60.3 \pm 9.8 ; 27$ men; BMI $29.1 \pm 4.5$ ) and 51 age-matched healthy volunteers (age range 40 to 83 years, $56.5 \pm 6.8 ; 22 \mathrm{men}$; BMI $28.4 \pm 4.8$ ) participated in the study. The proportion of males was lower in the patient group than in the control group (26.7\% versus $43 \%$, $\mathrm{p}=0.04)$. One additional patient accepted to participate but declined to complete the study protocol due to difficulty to attend an appointment. All participants denied having a history and having no medical record of otology, neurology, psychiatry, or orthopaedic disorders, postural hypotension, or exposure to ototoxic medication or unsafe noise levels. All had similar access to health care, but none were seeking it due to sensory or balance deterioration. Patients were receiving primary health care for diabetes and the most frequent medication was metformin (76.4\%, $95 \%$ C.I. $68.4-84.4 \%)$.
According to the occurrence of falls within the previous year, by the definition of the World Health Organization ${ }^{3}$, patients were classified in two groups (Table I):

I. 75 patients with no history of falls ( 34 to 84 years old). II. 26 patients with a history of falls (42 to 79 years old). After clinical evaluation, including bed-side head shaking and positional tests, all participants replied to a selfadministered questionnaire of symptoms related to balance, which was previously validated (Kurder Richardson $20=0.75$, intra-class rank correlation coefficient $=0.9)^{15}$. The questionnaire includes nine items to report each of the balance symptoms described in Fig. 1, with yes/no answers. A "no" response was scored 0 points and a "yes" response was scored 1 point, except for vertigo which was scored 2 points; frequent falls were considered when occurring at least once per month, and frequent stumbles when occurring at least once per week. The total score is calculated by adding all the points (range 0 to 10); a score higher than 3 can be related to balance disorders ${ }^{15}$.

Vestibular function was evaluated by sinusoidal rotation at $0.16 \mathrm{~Hz}$ and at $1.28 \mathrm{~Hz}\left(60^{\circ} / \mathrm{sec}\right.$ peak velocity), static visual vertical (average of 10 trials) and dynamic visual vertical during unilateral centrifugation $(300 \% \mathrm{sec}$ at 3.5 $\mathrm{cm}$ ) (I-Portal-NOCT-Professional, Neuro-Kinetics, Pittsburgh). For centrifugation, the chair was accelerated to $300 \% \mathrm{sec}$ in $60 \mathrm{sec}$; after $60 \mathrm{sec}$ of full speed rotation the chair moved from the center position to the right in 30 $\mathrm{sec}$, while in offset position the chair dwell for $60 \mathrm{sec}$, then it moved from the right position to the center in 30 sec, while in the center position it dwell for $60 \mathrm{sec}$, then it moved from the center position to the left in $30 \mathrm{sec}$, while in the offset position it dwell for $60 \mathrm{sec}$, then it moved from the left position to the center in $30 \mathrm{sec}$, and finally decelerated from $300^{\circ} / \mathrm{sec}$ to $0 \% \mathrm{~s}$ in $60 \mathrm{sec}$. Postural stability was evaluated using static posturography on hard and soft surface, with the eyes either open or closed (Posturolab 40/16, Cedex).

In patients with diabetes, peripheral neuropathy was evaluated at first by the Michigan Diabetic Neuropathy Score ${ }^{16}$ and the Semmes-Weinstein $10 \mathrm{~g}$ monofilament, when any of these two instruments was positive, nerve conduction studies were performed on the tibial and sural nerves (Spirit, Nicolet, Madison, U.S.A.) ${ }^{17}$.

Bivariate analysis was performed using "t" test (either for proportions or for means, accordingly), and multivariate analysis was performed using multiple regression and analysis of covariance (Statistica, Statsoft Inc., Tulsa). The significance level was set at 0.05 for two tails.

\section{Results}

In patients with diabetes mellitus, comparison between those with/without falls showed a similar age and BMI as well as a similar frequency of peripheral neuropathy, retinopathy and other clinical characteristics (Table I). 
Table I. Characteristics of 101 patients with type 2 diabetes mellitus with/without falls. Data is given as means and percentages with the $95 \% \mathrm{Cl}$.

\begin{tabular}{lccc} 
Characteristics of the patients & $\begin{array}{c}\text { Patients no falls } \\
(\mathbf{n = 7 5 )}\end{array}$ & $\begin{array}{c}\text { Patients with falls } \\
(\mathbf{n = 2 6 )}\end{array}$ & $\mathbf{P}^{*}$ \\
Female/male ratio & $52 / 24$ & $23 / 3$ & 0.001 \\
Years of age & $59.5(57.2-61.7)$ & $62.6(58.6-66.5)$ & $>0.1$ \\
Years of age at diagnosis & $47.0(44.7-49.2)$ & $51.6(48-55.2)$ & 0.03 \\
Years elapsed since diagnosis & $9.4(8.2-10.6)$ & $7.5(5.0-10.0)$ & $>0.1$ \\
Body mass index & $29(27.9-30)$ & $29.5(27.4-31.5)$ & $>0.1$ \\
Glycated haemoglobin & $7.8(7.0-8.7)$ & $7.6(7.2-7.9)$ & $>0.1$ \\
Peripheral neuropathy & $28 \%(18-38 \%)$ & $34 \%(16-52 \%)$ & $>0.1$ \\
Retinopathy & $6.5 \%(1-12 \%)$ & $12 \%(0-24 \%)$ & $>0.1$ \\
Polypharmacy & $34.6 \%(23.9-45.3 \%)$ & $38.4 \%(29.8-57 \%)$ & $>0.1$ \\
Hypertension & $48 \%(36.7 \%-59.3 \%)$ & $34 \%(15.8-52.2 \%)$ & $>0.1$ \\
Insulin use & $10.6 \%(3.7-17.5 \%)$ & $7.6 \%(0-17.7 \%)$ & $>0.1$ \\
\hline
\end{tabular}

However, patients with falls had a higher female/male ratio and were diagnosed later in life than patients with no falls (Table I).

Patients and controls had a similar gain to sinusoidal rotation at both $0.16 \mathrm{~Hz}$ and $1.28 \mathrm{~Hz}$ (Table II). However, compared to controls, patients with diabetes, either with or without a history of falls, showed an increased deviation of the static visual vertical and decreased responses to unilateral centrifugation ( $\mathrm{p}<0.01$ ) (Fig. 2, Table II). Multiple regression analysis showed a significant contribution to falls from the gender (beta $0.16,95 \%$ C.I. -0.02 $0.35)(\mathrm{R}=0.35, \mathrm{p}=0.008)$ and the total score of symptoms related to balance (beta $0.20,95 \%$ C.I. $0.1-39$ ), but no other significant relationships were observed. The frequency of patients with a total score suggesting a balance disorder $(\geq 4)$ was almost twice that in patients with falls $(57.7 \%, 95 \%$ C.I. $38.7-76.7 \%)$ than in patients with no falls $(32.5 \%$, 95\% C.I. 22.3-42.7\%) ("t'" test for proportions, $\mathrm{p} \leq 0.05)$. Among the items, a significant difference between the groups was observed on a larger proportion of patients with falls reporting frequent stumbles (Fig. 1) ("t" test for proportions, $\mathrm{p} \leq 0.05$ ), while in the two groups the most frequent symptoms were instability when changing posture and when moving the head rapidly (Fig. 1). Compared to healthy controls, during static posturogra-

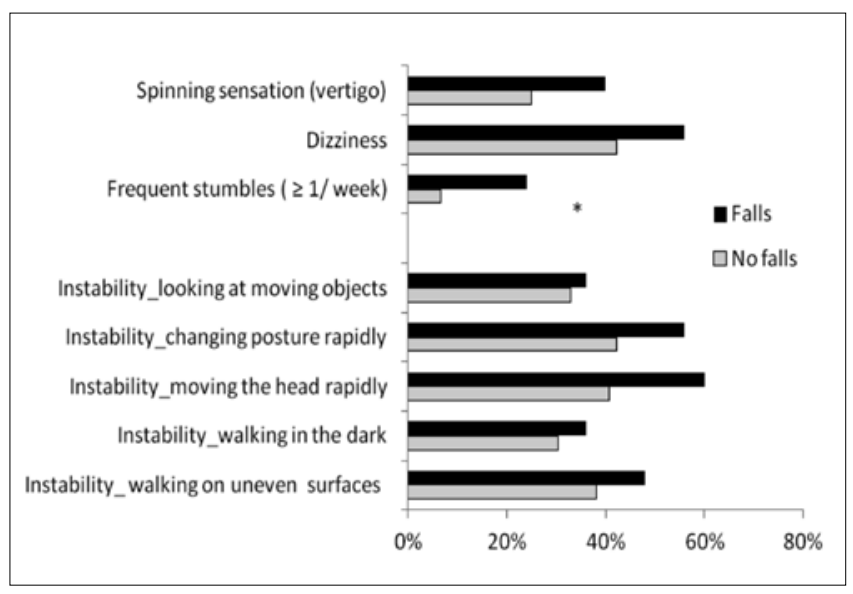

Fig. 1. Frequency of symptoms related to balance reported by 101 patients with type 2 diabetes mellitus, 26 with a history of falls and 75 with no history of falls.

phy patients with diabetes showed a larger area of sway while standing with the eyes open either on hard or soft surface, which was accompanied by a lengthier sway path (Table III).

Among patients with diabetes, the Romberg index, either on hard or soft surface, showed no significant difference

Table II. Vestibular evaluation of 101 patients with type 2 diabetes mellitus with/without falls and 51 age-matched volunteers without diabetes. Data is given as means and $95 \%$ Confidence Intervals. Comparisons between the control group and all the patients were performed using " $\mathrm{t}$ " test.

\begin{tabular}{|c|c|c|c|c|}
\hline \multirow[b]{2}{*}{ Vestibular test } & \multirow[b]{2}{*}{$\begin{array}{l}\text { Controls } \\
(n=51)\end{array}$} & \multicolumn{2}{|c|}{$\begin{array}{l}\text { Patients } \\
(n=101)\end{array}$} & \multirow[b]{2}{*}{$p$ value } \\
\hline & & $\begin{array}{l}\text { No falls } \\
(n=75)\end{array}$ & $\begin{array}{c}\text { Falls } \\
(n=26)\end{array}$ & \\
\hline Vestibulo-ocular reflex gain at $0.16 \mathrm{~Hz}$ & $0.54(0.48-0.59)$ & $0.53(0.48-0.59)$ & $0.54(0.46-0.61)$ & $>0.1$ \\
\hline Vestibulo-ocular reflex gain at $1.28 \mathrm{~Hz}$ & $0.96(0.93-1.0)$ & $0.93(0.90-0.96)$ & $0.94(0.89-0.99)$ & $>0.1$ \\
\hline Static visual vertical & $-0.14^{\circ}\left(-0.3-0.03^{\circ}\right)$ & $1.8^{\circ}\left(1.5-2.1^{\circ}\right)$ & $1.9^{\circ}\left(1.3-2.5^{\circ}\right)$ & $<0.01$ \\
\hline Dynamic visual vertical, right & $-5.0^{\circ}\left(-5.3--4.7^{\circ}\right)$ & $-2.8^{\circ}\left(-3.7--1.9^{\circ}\right)$ & $-1.4^{\circ}\left(-3.3--0.4^{\circ}\right)$ & $<0.01$ \\
\hline Dynamic visual vertical, left & $5.1^{\circ}\left(4.8-5.4^{\circ}\right)$ & $3.5^{\circ}\left(2.5-4.6^{\circ}\right)$ & $4.0^{\circ}\left(2.3-5.7^{\circ}\right)$ & 0.04 \\
\hline
\end{tabular}




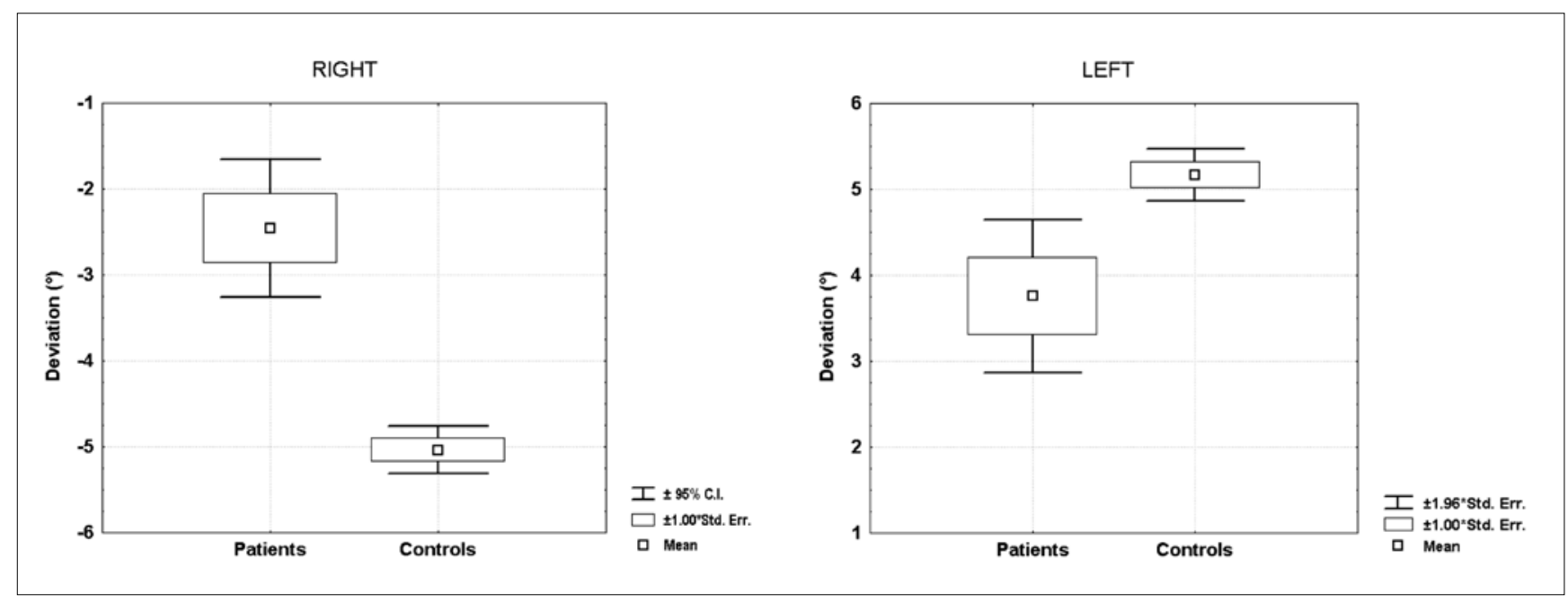

Fig. 2. Mean, standard error of the mean and $95 \%$ C.I. of the mean of the responses to unilateral centrifugation (to the right and to the left) of 101 patients with type 2 diabetes mellitus and 51 age-matched controls without diabetes.

between patients with/without falls $(\mathrm{p}>0.05$ ), and covariance analysis did not show any other significant relationship with the clinical characteristics of the patients. However, comparison between those with/without peripheral neuropathy showed that patients with no falls but neuropathy had a trend for a larger area of sway, with no lengthier sway path, while in patients with falls there was no consistent difference between those with or without neuropathy (Table III).

\section{Discussion}

Evaluation of patients with type 2 diabetes mellitus receiving primary health care who were not seeking care for balance disorders, compared to healthy volunteers, showed decreased responses to utricular stimulation by unilateral centrifugation, even when horizontal canal function at $0.16 \mathrm{~Hz}$ and $1.28 \mathrm{~Hz}$ was preserved, and a larger area of sway with a lengthier sway path on static posturography. These results suggest that, in patients with diabetes mellitus receiving primary health care an underlying otolith vestibular dysfunction may contribute to postural instability, which could enhance the effect of other sensory deficits and in turn may add to the risk factors for balance decline.

The finding of decreased utricular responses to unilateral centrifugation in patients with type 2 diabetes mellitus, even when horizontal canal function was preserved, is consistent with the dissociation between the responses to cervical and ocular vestibular-evoked myogenic potentials and head thrust dynamic visual acuity in all canal planes recently reported in patients with diabetes ${ }^{14}$. Although in that study the head thrust dynamic visual acuity testing showed semicircular canal dysfunction in at least one plane in $70 \%$ of patients, participants were all 50 years of age and older with $\geq 10$-year history of type 2 diabetes.
The different responses of the two end organs, otoliths and semicircular canals, in early stages of diabetes mellitus could be related to their metabolic and vascular characteristics. In murine models, evaluation of the local metabolic rate of glucose utilisation has shown similar results for the utricle and saccule, which were significantly higher than that for the superior, posterior, or lateral canal ampulla ${ }^{18}$. Compared to the posterior canal ampulla, the rat utricular macula is similar with respect to neuroepithelial volume, capillary surface area and blood flow, but the capillary diameter is smaller and the capillary length is greater ${ }^{19}$. This is consistent with the finding in rats with long-term experimental diabetes of increased capillary diameters along with increased vascularisation of the saccule, suggesting greater stress on the capillary wall ${ }^{20}$. In addition, the maculae of neither animal models nor human beings have shown microangiopathy, even if loss of type I hair cells has been described ${ }^{2021}$, while evidence supports that dysregulated energy metabolism could also have a role in the vestibular dysfunction due to diabetes mellitus in the context of insulin signaling networks ${ }^{22}$.

Vestibular dysfunction is a significant differential diagnosis in patients who have unexpected falls ${ }^{23}$, and in patients with peripheral neuropathy related to diabetes balance recovery after peripheral vestibular disease may be compromised ${ }^{24}$. However, in this study, the evidence of utricular dysfunction in both groups of patients (with/ without falls), with a similar frequency of peripheral neuropathy and a low frequency of retinopathy, did not allow the assessment of the interaction between sensory deficits. Likewise, the low frequency of insulin use and similar glycated haemoglobin levels in the two groups (Table I) did not allow an adequate assessment of a possible influence of these variables on vestibular function and postural control.

Although it is already known that during quiet stance patients with diabetes and peripheral neuropathy sway more 
Table III. Mean and 95\% confidence interval of the mean of the length of sway and area of sway of 101 patients with type diabetes mellitus with/without falls and with/without peripheral neuropathy, and 51 age-matched volunteers without diabetes mellitus.

\begin{tabular}{|c|c|c|c|c|c|c|c|c|c|}
\hline $\begin{array}{l}\text { Variables by } \\
\text { condition }\end{array}$ & $\begin{array}{l}\text { No falls } \\
\text { no neuropathy } \\
(\mathrm{n}=54)\end{array}$ & $\begin{array}{l}\text { No falls with } \\
\text { neuropathy } \\
(n=21)\end{array}$ & $\begin{array}{c}p \\
\text { value }\end{array}$ & $\begin{array}{c}\text { Falls } \\
\text { no neuropathy } \\
(\mathrm{n}=17)\end{array}$ & $\begin{array}{l}\text { Falls with } \\
\text { neuropathy } \\
(n=9)\end{array}$ & $\begin{array}{c}p \\
\text { value }\end{array}$ & $\begin{array}{l}\text { All patients } \\
(\mathrm{n}=101)\end{array}$ & $\begin{array}{l}\text { Controls } \\
(n=51)\end{array}$ & $\begin{array}{c}p \\
\text { value }\end{array}$ \\
\hline \multicolumn{10}{|c|}{ Hard surface with eyes open } \\
\hline Length of sway (mm) & $366(326-406)$ & $356(284-427)$ & $>0.1$ & $317(251-383)$ & $415(265-565)$ & $>0.1$ & $364(331-397)$ & 279 (259- 299) & $<0.001$ \\
\hline Area of sway $\left(\mathrm{mm}^{2}\right)$ & 108 (75-141) & $205(54-356)$ & 0.06 & $89(44-135)$ & $105(53-157)$ & $>0.1$ & 134 (88-181) & 69 (55- 83) & 0.03 \\
\hline \multicolumn{10}{|c|}{ Hard surface with eyes closed } \\
\hline Length of sway (mm) & $521(442-600)$ & $543(404-681)$ & $>0.1$ & $444(298-590)$ & $531(344-717)$ & $>0.1$ & $530(464-595)$ & 436 (398- 474) & 0.002 \\
\hline Area of sway $\left(\mathrm{mm}^{2}\right)$ & 166 (98-233) & 419 (87-751) & 0.02 & $114(51-176)$ & $182(45-319)$ & $>0.1$ & 237 (135-339) & $120(96-144)$ & 0.09 \\
\hline \multicolumn{10}{|c|}{ Soft surface with eyes open } \\
\hline Length of sway (mm) & $473(410-535)$ & $487(383-592)$ & $>0.1$ & $398(347-449)$ & $534(328-740)$ & 0.07 & $479(427-530)$ & $370(339-400)$ & 0.06 \\
\hline Area of sway $\left(\mathrm{mm}^{2}\right)$ & $177(116-239)$ & $343(117-568)$ & 0.05 & 148 (96-199) & $239(94-385)$ & $>0.1$ & $226(151-301)$ & $118(96-140)$ & 0.01 \\
\hline \multicolumn{10}{|c|}{ Soft surface with eyes closed } \\
\hline Length of sway (mm) & $792(664-919)$ & $695(563-828)$ & $>0.1$ & $599(428-770)$ & 807 (482-1131) & $>0.1$ & $768-(672-864)$ & 607 (554- 660) & 0.02 \\
\hline Area of sway (mm²) & 495 (316-674) & 546 (300-792) & $>0.1$ & 236 (146-326) & 433 (177-689) & 0.05 & $513(372-654)$ & 276 (217- 334) & 0.02 \\
\hline
\end{tabular}

than controls and even more so if their visual or vestibular systems are perturbed ${ }^{25}$. In this study, patients with diabetes, compared to healthy controls, showed a larger area of sway and a lengthier sway path. However, those with no history of falls but neuropathy had a trend for a larger area of sway, while those with falls, either with or without neuropathy, showed more variability on their sway path. This finding supports that peripheral neuropathy may interact with other sensory impairments and factors related to postural coordination underling balance decline. In this study, the sample size as well as the low frequency of retinopathy in patients with/without a history of falls may preclude further discussion on the interaction among sensory deficiencies.

Among patients with diabetes, a gender influence on falling was evident. The association between female gender and higher risk of falls has been described previously ${ }^{3}$. This finding could be at least partially related to muscle strength. Age-related decline in muscle quality is more pronounced in women than men ${ }^{26}$, as well as age related hallux plantar-flexion strength decrease ${ }^{27}$.

The results of this study should be interpreted in the context of its limitations. Since utricular hypofunction was evident in patients with/without falls, and no additional tests were performed, its contribution to postural instability cannot be assessed adequately. Since the evaluation of the occurrence of falls was by self-report, inaccuracy cannot be excluded. In this study, patients were recruited in a primary health care setting, with a low frequency of both complications and polypharmacy, with no history of otologic, neurologic, or orthopaedic disorders. Thus, in patients with more physical impairments the results may be different. According to the cross-sectional design of the study, the findings cannot exclude that patients may develop other vestibular dysfunction in the future. Longitudinal studies are needed to assess the development of the vestibular damage related to diabetes mellitus and its influence on postural control.

\section{Conclusions}

In conclusion, in patients with type 2 diabetes mellitus receiving primary health care, who are not seeking medical care due to sensory or balance decline, utricular function may be impaired even in the absence of semicircular canal dysfunction or a history of falls, and the occurrence of falls may not be independently related to vestibular function.

\section{Acknowledgements}

We thank Niels Watcher Rodarte for his valuable collaboration, as well as Rita Gómez Díaz and Anabel Meza Urquiza for their contribution to identify candidates to participate in the study and Teresa Mantilla-Ochoa and Lilia Zainos-Saucedo for their contribution to perform nerve conduction studies. The study was supported by CONACyT SALUD-2010-02-151394 and IMSS FIS/ IMSS/PROT/1034.

\section{References}

1 Jáuregui-Renaud K, Kovacsovics B, Vrethem M, et al. Dynamic and randomized perturbed posturography in the follow-up of patients with polyneuropathy. Arch Med Res 1998;29:39-44.

2 Agrawal Y, Carey J, Della Santina C, et al. Diabetes, Vestibular dysfunction, and falls: analyses from the National Health and Nutrition Examination Survey. Otol Neurotol 2010;31:1445-50.

3 World Health Organization. WHO Global report on falls prevention in older age. Epidemiology of falls. Available at: www.who.int/ageing/publications/Falls_prevention7March. pdf 
4 Roman de Mettelinge T, Cambier D, Calders P, et al. Understanding the relationship between type 2 diabetes mellitus and falls in older adults: a prospective cohort study. PLoS One 2013;8, e67055.

5 Yau RK, Strotmeyer ES, Resnick HE, et al. Diabetes and risk of hospitalized fall injury among older adults. Diabetes Care 2013;36:3985-91.

6 Schwartz AV, Vittinghoff E, Sellmeyer DE, et al. Diabetesrelated complications, glycemic control, and falls in older adults. Diabetes Care 2008;31:391-6.

7 Gregg EW, Beckle G, Williams DF, et al. Diabetes and physical disability among older U.S. adults. Diabetes Care 2000;23:1272-7.

8 Herrera- Rangel A, Aranda-Moreno C, Mantilla-Ochoa MT, et al. Awareness of sensory decline in patients with type 2 diabetes mellitus. Int J Diabetes Dev Ctries 2015;35:s458-60.

9 Jáuregui-Renaud K, Sánchez BM, Ibarra-Olmos A, et al. Neuro-otologic symptoms in patients with type 2 diabetes mellitus. Diabet Res Clin Pract 2009;84:e45-7.

10 Perez R, Ziv E, Freeman S, et al. Vestibular end-organ impairment in an animal model of type 2 diabetes mellitus. Laryngoscope 2001;111:110-3.

11 Myers SF. Myelin-sheath abnormalities in the vestibular nerves of chronically diabetic rats. Otolaryngol Head Neck Surgery 1998;119:432-8.

12 Özel HE, Özkiriş M, Gencer ZK, et al. Audiovestibular functions in noninsulin-dependent diabetes mellitus. Acta Otolaryngol 2014;134:51-7.

13 Abdul Razzak R, Hussein W. Postural visual dependence in asymptomatic type 2 diabetic patients without peripheral neuropathy during a postural challenging task. J Diabetes Complications 2016;30:501-6.

14 Ward BK, Wenzel A, Kalyani RR, et al. Characterization of vestibulopathy in individuals with type 2 diabetes mellitus. Otolaryngol Head Neck Surg 2015;153:112-8.

15 Jáuregui-Renaud K, Gutiérrez MA, Viveros RL. Síntomas de inestabilidad corporal y enfermedad vestibular. Rev Med Instit Mex Seguro Soc 2003;41:373-8.

16 Feldman EL, Stevens MJ, Thomas PK, et al. A practical twostep quantitative clinical and electrophysiological assess- ment for the diagnosis and staging of diabetic neuropathy. Diabetes Care 1994;17:1281-9.

17 England JD, Gronseth GS, Franklin G, et al. American Academy of Neurology; American Association of Electrodiagnostic Medicine; American Academy of Physical Medicine and Rehabilitation. Distal symmetric polyneuropathy: a definition for clinical research: report of the American Academy of Neurology, the American Association of Electrodiagnostic Medicine, and the American Academy of Physical Medicine and Rehabilitation. Neurology 2005;64:199-207.

18 Olds MJ, Lyon MJ. Glucose utilization of the rat vestibular end organs: a quantitative 2-deoxyglucose study. Ann Otol Rhinol Laryngol 1997;106:145-50.

19 Payman R, Lyon MJ. Rat utricular macula: blood flow and stereological assessment of capillary morphology. Ann Otol Rhinol Laryngol 1993;102:893-9.

20 Myers SF, Ross MD, Jokelainen P, et al. Morphological evidence of vestibular pathology in long-term experimental diabetes mellitus. I. Microvascular changes. Acta Otolaryngol 1985;100:351-64.

21 Kocdor P, Kaya S, Erdil M, Cureoglu S, et al. Vascular and neuroepithelial histopathology of the saccule in humans with diabetes mellitus. Otology Neurotol 2016;37:553-7.

22 Degerman E, Rauch U, Lindberg S, et al. Expression of insulin signalling components in the sensory epithelium of the human saccule. Cell Tissue Res 2013;352:469-78.

23 Pothula VB, Lesser THJ, Sharma AK. Falls and vestibular impairment. Clin Otolaryngol All Sci 2004;29:179-82.

24 Aranda-Moreno C, Meza A, Rodriguez R, et al. Diabetic polyneuropathy may increase the handicap related to vestibular disease. Arch Med Res 2009;40:180-5.

25 Bonnet CT, Ray C. Peripheral neuropathy may not be the only fundamental reason explaining increased sway in diabetic individuals. Clin Biomech 2011;26:699-706.

26 Doherty TJ. The influence of aging and sex on skeletal muscle mass and strength. Curr Opin Clin Nutr Metab Care 2001;4:503-8.

27 Menz HB, Zammit GV, Munteanu SE, et al. Plantar flexion strength of the toes: age and gender differences and evaluation of a clinical screening test. Foot Ankle Int 2006;27:1103-8.

Address for correspondence: Kathrine Jáuregui-Renaud, Unidad de Investigación Médica en Otoneurología, Planta baja del Edificio CSalud en el Trabajo, Centro Médico Nacional siglo XXI, IMSS, Av. Cuauhtémoc 330, Colonia Doctores, 06720 México D.F. Tel. 5255 562769 00. E-mail: kathrine.jauregui @imss.gob.mx 